\title{
Pengembangan Media Pembelajaran Matematika Menggunakan Adobe Flash berupa Alur Cerita Anime Pokok Bahasan Aritmatika Sosial
}

\author{
Muhammad Salahuddin ${ }^{1)}$, Nursidarati ${ }^{2)}$, Firnanda Pradana Putra ${ }^{3)}$, Lisda Ramdhani ${ }^{4)}$ \\ ${ }^{1,2,4)}$ Sekolah Tinggi Keguruan dan Ilmu Pendidikan Harapan Bima \\ ${ }^{3)}$ Institut Agama Islam Negeri Samarinda \\ Email: muh.ahlan07@gmail.com ${ }^{1)}$, nursidrati@gmail.com ${ }^{2)}$, pradana.0712@gmail.com ${ }^{3)}$ \\ lisdaramdhani1227@gmail.com ${ }^{4}$
}

\begin{abstract}
Abstrak. Tujuan penelitian adalah mengembangkan media pembelajaran matematika berbasis macromedia flash sebagai media pembelajaran matematika SMP pada pokok bahasan aritmatika sosial di kelas VII yang valid, praktis dan interaktif untuk kemudian diuji cobakan guna melihat efek potensial media pembelajaran berbasis macromedia flash bahasan aritmatika sosial terhadap pemahaman konsep siswa. . Model pengembangan yang digunakan mengacu pada model pengembangan ADDIE yang terdiri dari lima tahapan yaitu yaitu analysis, design, development, implementation dan evaluation. Hasil penelitian menunjukan bahwa media pembelajaran valid dengan dikategorikan cukup valid dari keseluruhan aspek dari lembar validasi media pembelajaran. Dari hasil penggunaan media dalam pembelajaran menunjukan bahwa media sudah layak digunakan sebagai media pembelajaran yang diketahui dari lembar angket siswa yang memenuhi aspek - aspek yang ada pada lembar angket siswa dengan dikategorikan baik.
\end{abstract}

\section{Kata kunci: Media Pembelajaran, Adobe Flash, Desain Pengembangan ADDIE.}

\section{PENDAHULUAN}

Media merupakan salah satu faktor yang turut menentukan keberhasilan pengajaran karena media membantu siswa dan guru dalam menyampaikan materi pelajaran sehubung dengan tujuan pengajaran. Penggunaan media dalam pembelajaran itu sendiri dapat meningkatkan motivasi siswa dalam belajar matematika (Bakar, Ayub, \& Luan, 2010). Dalam kondisi ini penggunaan media pembelajaran dapat meningkatkan efesiensi proses dan kualitas hasil belajar mengajar (Rivai dan Sudjana, 2001). Upaya yang akan dilakukan melalui media pembelajaran yang bervariatif dan inovatif, dengan adanya media pemebelajaran diharapkan dapat menumbuhkan rasa senang dan cinta dalam pembelajaran matematika. Penggunaan media dalam proses pembelajaran merupakan salah satu upaya untuk menciptakan pembelajaran yang lebih bermakna dan berkualitas. Menurut Latuheru (1988) penggunaan media dalam proses pembelajaran bertujuan agar proses pembelajaran dapat berlangsung secara tepat dan efektif sehingga mutu pendidikan dapat ditingkatkan. Menurut Hamalik (dalam
Arsyad, 2011) mengemukakan bahwa pemakaian media pembelajaran dalam proses belajar mengajar dapat membangkitkan keinginan dan minat bagi siswa, membangkitkan motivasi, rangsangan kegiatan belajar, dan bahkan membawa pengaruh psikologis yang baik pada siswa. Selain itu penggunaan media mempengaruhi kognitif siswa yang dapat membangun pengetahuan sehingga pembelajaran bermakna dapat terjadi (Kassim, 2013).

Berbagai penelitian yang telah dilakukan terhadap penggunaan media pembelajaran dalam proses belajar mengajar sampai pada kesimpulan bahwa proses dan hasil belajar siswa menunjukkan perbedaan yang berarti antara pembelajaran tanpa media dengan pembelajaran menggunakan media. Oleh sebab itu penggunaan media pembelajaran dalam proses belajar mengajar sangat dianjurkan untuk mempertinggi kualitas pembelajaran termasuk di dalamnya media komputer (Sudjana \& Rivai, 2011). Media pembelajaran yang dianggap cocok dan inovatif adalah media pembelajaran berbantuan komputer. 
Rusman (2013) menyatakan bahwa dalam peningkatan mutu pembelajaran secara garis besar komputer dimanfaatkan dalam dua macam penerapan yaitu dalam bentuk pembelajaran dengan bantuan komputer atau Computer Assited Instruction (CAI) dan pembelajaran berbasis komputer atau Computer Based Instruction (CBI). Pada CAI perangkat lunak yang digunakan berfungsi membantu guru dalam proses pembelajaran seperti multimedia, alat bantu presentasi, maupun sebagai alat bantu demonstrasi dalam pelaksanaan pembelajaran. Sementara pada CBI, komputer digunakan sebagai perangkat sistem pembelajaran, bahkan sistem pembelajaran dilaksanakan secara individual (individual learning) dan mandiri serta menerapkan sistem prinsip belajar tuntas (mastery learning) dan individual learning. CAI atau pembelajaran dengan bantuan komputer lebih dominan dalam meningkatkan kualitas pembelajaran, dimana pembelajaran dengan bantuan komputer dapat memfasilitas guru dan siswa untuk belajar bervariasi dan menyenangkan. Dengan bantuan komputer sebuah media pembelajaran dapat diciptakan untuk menunjang kegiatan pembelajaran yang berkualitas. Salah satu media pembelajaran berbasis komputer yang digunakan adalah media pembelajaran yang dapat menghadirkan suasana yang menyenangkan dan interaktif bagi siswa adalah media berbasis komputer dengan menggunakan software flash dengan Adobe macromedia flash.

\section{Flash adalah program untuk} menggambar grafis dan animasi yang dipasang pada website. Program ini berbasis pada vektor grafis, namun demikian juga dapat diisi dengan bitmap yang diimpor dari program lain (Yudhiantoro, 2003). Adobe Flash adalah salah satu perangkat lunak komputer yang merupakan produk ungulan Adobe Systems. Adobe Flash digunakan untuk membuat gambar vektor maupun animasi gambar. Adobe Flash CS5 Professional adalah sebuah program animasi yang telah banyak digunakan oleh para animator untuk menghasilkan animasi yang professional. Di antara program-program animasi, program
Adobe Flash CS5 Professional merupakan program yang paling fleksibel dalam pembuatan animasi, seperti animasi interaktif, game, company profile, presentasi, movie, ecard dan animasi yang digunakan dalam situs web (Madcoms, 2008). Selain itu Adobe flash mempunyai fungsi keunggulan serta kekurangan, salah satu fungsi Adobe Flash CS5 Professional Software Adobe Flash CS5 Professional sangat berguna dalam mendukung kesuksesan sebuah presentasi dan proses belajar mengajar (PBM). Dalam Adobe Flash CS5 Professional, kita dapat memasukan elemen-elemen seperti gambar atau movie, animasi, presentasi, dan game. Dapat digunakan sebagai tool untuk mendesain web, dan berbagai aplikasi multimedia lainnya.

Keunggulan program Adobe Flash CS5 Professional dibanding dengan program lain yang sejenis, antara lain adalah a) Dapat membuat tombol interaktif dengan sebuah movie atau objek yang lain. b) Dapat membuat transparansi warna dalam movie. c) Membuat perubahan animasi dari suatu bentuk kebentuk yang lain. d) Dapat membuat gerakan animasi dengan mengikuti alur yang telah di tetapkan. e) Dapat dikonversi dan diduplikasi (publish) ke dalam beberapa tipe (diantaranya adalah: swf, html, gif, jpg, png, exe mov) (Madcoms, 2004). Kekurangan dari program aplikasi Flash antara lain adalah sebagai berikut: a) Komputer yang ingin memainkan animasi flash harus memiliki flash player dan harus menginstallnya. b) Program adobe flash bukan freeware. c) Grafisnya kurang lengkap. d) Menunya tidak user friendly. e) Bahasanya pemrogramannya agak susah. f) Kurang dalam 3D. Pembuatan animasi 3D cukup sulit. g) Belum ada template didalamnya. (Elisa, http://elisaflorida. wordpress.com/2013/07/29/flash/)

\section{METODE PENELITIAN}

\section{Jenis Penelitian}

Jenis penelitian yang digunakan adalah penelitian Research and Development. Menurut Borg dan Gall (dalam Setyosari,2013), penelitian pengembangan 
adalah suatu proses yang dipakai untuk mengembangkan dan memvalidasi produk pendidikan.

\section{Desain Penenelitian}

Desain yang digunakan oleh peneliti dalam penelitian ini adalah pengembangan ADDIE. Branch (2009) menyatakan "ADDIE is an acronym from Analyze, Design, Develop, Implement and Evaluate. ADDIE is a product development concept. The ADDIE concept is being applied here contructing performance based learning." Seperti yang di sampaikan oleh Branch desain pengembangan ADDIE yang meliputi 5 tahap yang digunakan dalam penelitian ini yaitu sebagai berikut.

\subsection{Analysis (Analisis)}

Pada tahap ini dilakukan aktivitas berupa menetapkan dan mendefinisikan kebutuhan - kebutuhan pembelajaran dengan menganalisis tujuan dan batasan materi. Analisa yang dilakukan meliputi karakteristik siswa, kebutuhan sekolah, kegiatan pembelajaran di sekolah, metode guru, kompetensi dasar dan kompetensi inti, produk (model, metode, media, bahan ajar) baru yang akan dikembangkan; mengidentifikasi produk yang sesuai dengan sasaran siswa, tujuan belajar, mengidentifikasi isi atau materi pembelajaran, mengidentifikasi lingkungan belajar dan strategi penyampaian dalam pembelajaran.

\subsection{Design (Perencanaan)}

Berisi perancangan alur pembelajaran agar media yang akan dirancang sistematis dan terarah dalam proses pembuatan. Membuat rancangan media pembelajaran dengan software Adobe Flash CS5 Professional.

\subsection{Development (Pengembangan)}

Tahap pengembangan berisi beberapa penilaian oleh tim penilai, yang meliputi penilaian oleh ahli materi, dan ahli media.

\subsection{Implementation (Implementasi)}

Tahap ini merupakan implementasikan rancangan dan metode yang telah dikembangkan pada kondisi yang sebenarnya yaitu di dalam kelas, materi yang disampaikan sesuai dengan model/metode yang baru dikembangkan setelah dilakukan evaluasi awal disertai respon guru dan respon siswa sebagai pelaksana pembelajaran.

\subsection{Evaluation (Evaluasi)}

Pada tahap ini aktivitas yang dilakukan adalah melihat kembali dampak pembelajaran dengan cara yang kritis, mengukur ketercapaian tujuan pengembangan produk, mengukur apa yang telah mampu dicapai oleh sasaran, dan mencari informasi apa saja yang dapat membuat siswa mencapai hasil dengan baik. Desain dalam penelitian ini menggunakan tahapan sebagai berikut.

\section{Instrumen Pengumpulan Data}

Instrumen yang digunakan untuk mengumpulkan data pada penelitian ini terdiri dari:

\subsection{Lembar Validasi media pembelajaran untuk ahli media}

Lembar validasi media pembelajaran terdiri skala penilaian 1-4 digunakan untuk mengetahui kualitas produk media yang dikembangkan dengan menggunakan angket penilaian. Angket penilaian terdiri dari 1). Isi media pembelajaran dengan aspek-aspek yang dinilai a) media pembelajaran dapat membantu siswa belajar matematika, b) media pembelajaran dapat membantu siswa membangun pemahamaman matematika, c) kegiatan yang diberikan memungkinkan adanya interaksi yang positif anatara siswa dengan media pembelajaran d) kegiatan yang terdapat dalam penggunaan media pembelajaran sesuai dengan tujuan pembelajaran, e) media pembelajaran tidak menimbulkan ambigu. 2) Gambar dan animasi dengan aspek yang dinilai: a) media pembelajaran disertai dengan gambar dan konsep animasi yang sesuai dengan materi atau konsep yang dibahas, b) gambar dan animasi yang digunakan memperjelas materi pembelajaran, c) gambar dan animasi yang disajikan menarik, d) gambar dan animasi yang disajikan sesuai dengan siswa SMP. 3) kegunaan media pembelajaran dengan aspek yang dinilai: a) dapat digunakan untuk membantu siswa dalam mencapai tujuan pembelajaran, b) dapat digunakan sebagai pendukung pembelajaran matematika di 
sekolah, c) dapat mendorong siswa untuk lebih aktif. 4) Bentuk dan tampilan dengan apek yang dinilai a) tampilan media pembelajaran menarik, b) bentuk media proposioanal. 4) Bahasa dan simbol dengan aspek yang dinilai a) bahasa yang digunakan komunikatif, b) tampilan warna, jenis font, ukuran font yang digunakan menarik bagi siswa.

Tabel 1. Kriteria Kevalidan Media

\begin{tabular}{cc}
\hline Rata - rata nilai & Kriteria Validitas \\
\hline $3,51-4,00$ & Sangat Valid \\
\hline $3,01-3,50$ & Cukup Valid \\
\hline $2,01-3,00$ & Kurang Valid \\
\hline $1,00-2,00$ & Tidak Valid \\
\hline
\end{tabular}

\subsection{Lembar Observasi Kegiatan Pembelajaran}

Lembar observasi kegiatan pembelajaran terdiri skala penilaian 1-4 digunakan untuk mengetahui kesesuain antara pelaksanaan pembelajaran di kelas yang dikembangkan dengan menggunakan angket penilaian. Angket observasi kegiatan pembelajaran terdiri dari 1) Kegiatan Pendahuluan dengan apek yang dinilai a) guru mempersiapkan media pembelajaran yang digunakan, b) guru menjelaskan cara penggunaan media pembelajaran, c) guru memberikan apersepsi sesuai dengan materi yang akan dipelajari, d) guru menyampaikan tujuan pembelajaran, e) siswa mengikuti kegiatan pendahuluan, f) guru membagi siswa dalam beberapa kelompok. 2) Kegiatan Inti dengan aspek yang dinilai a) siswa terlibat dalam penggunaan media pembelajaran, b) siswa antusias dalam penggunaan media pembelajaran, c) media dapat membantu siswa dalam pembalajaran. 3) Kegiatan penutup dengan aspek yang dinilai a) guru melaksanakan kegiatan refleksi, b) guru mengarahkan siswa untuk menyimpulkan pembelajaran hari ini.

\subsection{Lembar Angket untuk siswa}

Lembar observasi kegiatan
pembelajaran terdiri skala penilaian 1-4 digunakan untuk mengetahui apakah media membantu siswa dalam pembelajaran yang dikembangkan dengan menggunakan angket penilaian. Angket penilaian oleh siswa terdiri dari 1) tampilan media dengan aspek yang dinilai a) media mudah digunakan, b) tidak menimbulkan ambigu dalam memahami konsep, c) petunjuka penggunaan media jelas. 2) Konten media dengan aspek yang dinilai a) media menuntun siswa untuk memahami konsep, b) kesesuaian media terhadap tujuan pembelajaran, c) konsep kesebangunan dan kekongruenan disajikan sesuai dengan kebenaran keilmuan, d) permasalahan dalam media memungkinkan siswa terampil mengerjakan soal. 3) Sajian konten dengan aspek yang dinilai a) interaksi antara siswa dengan media sudah terlihat, b) media yang dibuat jelas dan berkaitan dengan materi. 4) Desain dan tata letak media dengan aspek yang dinilai desain tampilan media menarik.

Tabel 2. Kriteria Lembar Obsevasi Kegiatan Pembelajaran dan Angket Siswa

\begin{tabular}{cc}
\hline Rata - rata nilai & Kriteria \\
\hline $3,51-4,00$ & Sangat Baik \\
\hline $3,01-3,50$ & Baik \\
\hline $2,01-3,00$ & Cukup Baik \\
\hline $1,00-2,00$ & Kurang Baik \\
\hline
\end{tabular}

HASIL DAN PEMBAHASAN 1.Penyusunan Media Pembelajaran

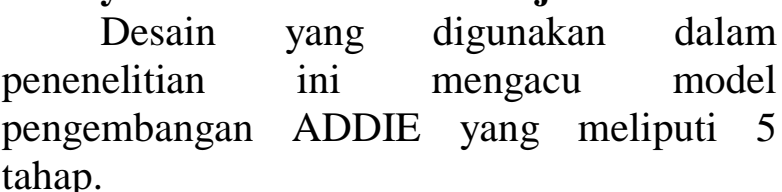
a. Tahap Analisis (Analysis)

Tahap paling awal dari sebuh penelitian R n D adalah analisis kebutuhan. Peneliti memulai dari analisis kurikulum yang digunakan dibanyak sekolah/madrasah, yaitu kurikulum 2013 atau K13. Sesuai dengan permendikbud No. 24 Tahun 2016 tentang standar isi mata pelajaran matematika tingkat sekolah menengah pertama atau MTs. Kompetensi Dasar yang digunakan dalam penelitian ini yaitu mengenal dan menganalisis berbagai situasi terkait aritmetika sosial (penjualan, pembelian, potongan, keuntungan, kerugian, bunga tunggal, persentase, bruto, neto, tara. 


\section{b. Tahap Perencanaan (Design)}

Pada perencanaan menjelaskan mengenai rancangan media pembelajaran. Hasil dari tahap ini berupa rancangan kerangka media pembelajaran berbasis Adobe Flash CS5 berdasarkan materi aritmatika sosial yang telah disusun. Berdasarkan Kompetensi Dasar dan kesiapan materi yang deigunakan pada media pembelajaran, adapun kerangka media pembelajaran sebagai berikut.

a) Saat program dijalankan maka akan tampil layar utama identitas dari pembuat media dan akan mucul menu login, setelah login langsung menuju menu utama.

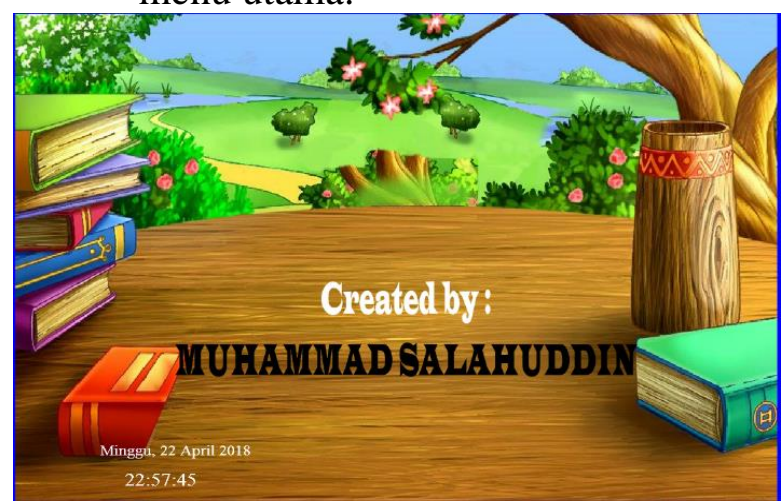

b) Pada menu utama berisi beberapa pilihan menu, yaitu: main, latihan soal dan review soal



c) Pada menu main, akan langsung menuju permainan berupa pertualang sambil belajar materi aritmatika.
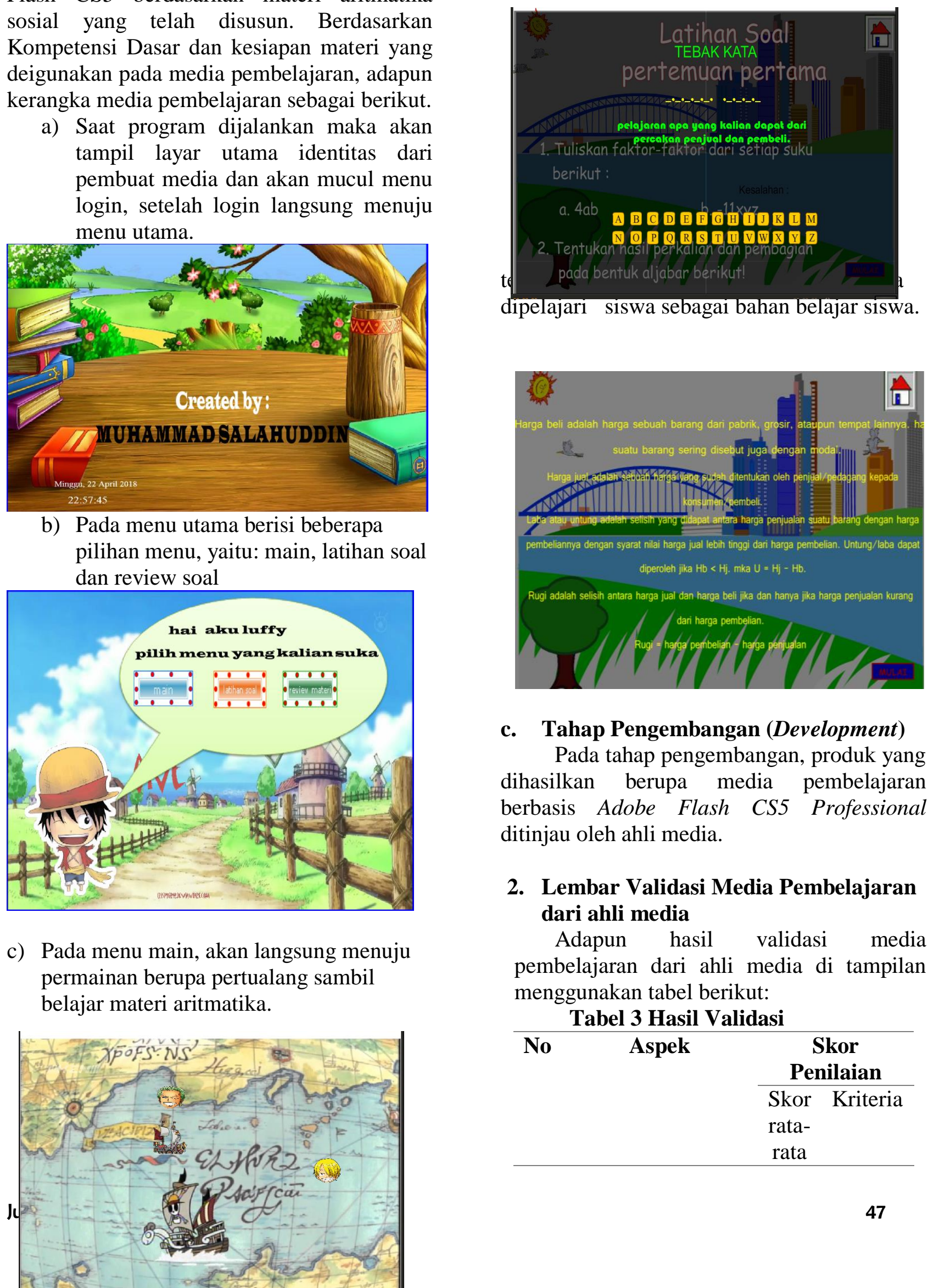

\section{c. Tahap Pengembangan (Development)}

Pada tahap pengembangan, produk yang dihasilkan berupa media pembelajaran berbasis Adobe Flash CS5 Professional ditinjau oleh ahli media.

\section{Lembar Validasi Media Pembelajaran dari ahli media}

Adapun hasil validasi media pembelajaran dari ahli media di tampilan menggunakan tabel berikut:

\section{Tabel 3 Hasil Validasi}

\begin{tabular}{cc}
\hline No Aspek & $\begin{array}{c}\text { Skor } \\
\text { Penilaian }\end{array}$ \\
\cline { 2 - 2 } & $\begin{array}{c}\text { Skor Kriteria } \\
\text { rata- } \\
\text { rata }\end{array}$
\end{tabular}




\begin{tabular}{llrl}
\hline $\mathbf{1}$ & $\begin{array}{l}\text { Isi Media } \\
\text { Pembelajaran }\end{array}$ & 3,20 & $\begin{array}{l}\text { Cukup } \\
\text { valid }\end{array}$ \\
\hline $\mathbf{2}$ & $\begin{array}{l}\text { Gambar dan } \\
\text { animasi (Untuk } \\
\text { Media Komputer) }\end{array}$ & 3,25 & $\begin{array}{l}\text { Cukup } \\
\text { valid }\end{array}$ \\
\hline $\mathbf{3}$ & $\begin{array}{l}\text { Kegunaan Media } \\
\text { Pembelajaran }\end{array}$ & 3,00 & $\begin{array}{l}\text { Cukup } \\
\text { valid }\end{array}$ \\
\hline $\mathbf{4}$ & $\begin{array}{l}\text { Bentuk dan } \\
\text { Tampilan }\end{array}$ & 3,00 & $\begin{array}{l}\text { Cukup } \\
\text { valid }\end{array}$ \\
\hline $\mathbf{5}$ & $\begin{array}{l}\text { Bahasa dan } \\
\text { symbol }\end{array}$ & 3,00 & $\begin{array}{l}\text { Cukup } \\
\text { valid }\end{array}$ \\
\hline
\end{tabular}

Lembar validasi media pembelajaran oleh ahli menunujukan bahwa media pembelajaran yang akan digunakan sudah valid dengan dikategorikan baik dari keseluruhan aspek, tetapi adapun saran dan masukan dari ahli media yaitu 1) percakapan pada media pembelajaran perlu diperbaiki, 2) format tulisan dan tombol diperhatikan dan ditambahkan tombol next pada percakapan, 3) gambar anime di buat lebih menarik dan 4) perlu ditekankan pada aspek konstruktivisme siswa, 5) pembelajaran belum sampai pada penggunaan rumus mengenai laba dan rugi, dan perlu ditambahkan rumus dan penggunaan rumus rugi dan laba tersebut.

\section{Lembar Observasi Kegiatan \\ Pembelajaran}

Lembar Observasil Kegiatan pembelajaran digunakan untuk mengetahui kesesuaian natara RPP pembelajaran yang di buat dengan pelaksanaan pembelajaran di kelas. Adapun hasil Observasi Kegiatan Pembelajaran ditampilkan pada tabel berikut

Tabel 4 Hasil Observasi Kegiatan Pembelajaran

\begin{tabular}{llll}
\hline No & Deskripsi & $\begin{array}{l}\text { Skor } \\
\text { rata }- \\
\text { rata }\end{array}$ & kategori \\
\hline $\mathbf{1}$ & Pendahuluan & 2,5 & Cukup baik \\
\hline $\mathbf{2}$ & Inti & 4 & $\begin{array}{l}\text { Sangat } \\
\text { baik }\end{array}$ \\
\hline $\mathbf{3}$ & Penutup & 3 & Cukup baik \\
\hline
\end{tabular}

Hasil observasi kegiatan pembelajaran kekurangannya ada pada pendahuluan dengan kategori cukup dikarenakan guru kurang memperhatikan langkah - langkah pembelajaran pada awal pembelajaran yang merupakan pendahuluan. Adapun saran dan masukan dari hasil observasi kegiatan pembelajaran yaitu 1) loading masuk pada media pembelajaran jangan terlalu lama, 2) bahasa yang digunakan lebih diperhatikan lagi, dan 3) desain yang ditampilkan sudah bagus.

\section{Lembar Angket Siswa}

Lembar angket siswa digunakan untuk mengetahui efektif dan kepratisan media pembelajaran dalam pembelajaran dan mengetahui media dapat membantu siswa dalam pembelajaran. Hasil lembar angket siswa ditampilkan pada tabel berikut.

\section{Tabel 5 Lembar Angket Siswa}

\begin{tabular}{|c|c|c|c|c|c|c|c|c|c|c|c|}
\hline $\mathrm{N}_{0}$ & Deshripsi & $\begin{array}{l}\text { Rata - } \\
\text { ratta } 51\end{array}$ & $\begin{array}{l}\text { Rata- } \\
\text { nata S? }\end{array}$ & $\begin{array}{l}\text { Rata - } \\
\text { rata S S }\end{array}$ & $\begin{array}{l}\text { Rita - } \\
\text { rata St }\end{array}$ & $\begin{array}{c}\text { Rath - nata } \\
35\end{array}$ & $\begin{array}{l}\text { Rata- } \\
\text { nath S6 }\end{array}$ & $\begin{array}{l}\text { Rata - } \\
\text { rata St? }\end{array}$ & $\begin{array}{c}\text { Ratia- ratat } \\
\text { S8 }\end{array}$ & $\begin{array}{c}\text { Jumlahriata- } \\
\text { ratata }\end{array}$ & Kalegori \\
\hline 11 & TamolanNedia & 3,00 & 2,67 & 3,00 & 2,67 & 2,67 & 3,00 & 3,00 & 3,33 & 292 & Cylup \\
\hline 1 & KontenMedia & 3,00 & 3,50 & 2,25 & 3,00 & 3,00 & 3,25 & 3,00 & 325 & 3,03 & Salk \\
\hline 3 & sajan & 3,50 & 3,50 & 3,00 & 3,50 & 2,50 & 2,5 & 3,00 & 3.50 & 3,13 & Balk \\
\hline 4 & $\begin{array}{l}\text { Desaindantata } \\
\text { letakKedia }\end{array}$ & 3,00 & 4,00 & 1,00 & 3,00 & 3,00 & 4,00 & 4,00 & 4,00 & 3,25 & Balk \\
\hline
\end{tabular}

Dari hasil hasil lembar angket siswa dapat diketahui bahwa media pembelajaran yang dihasilkan dapat digunakan dalam pembelajaran dan memenuhi aspek - aspek yang ada pada lembar angket siswa dengan dikategorikan baik. Namun media yang dihasilkan mempunyai banyak kekurangan sehingga saran dan masukan siswa dari lembar angket yaitu 1) pada saat percakapan lebih baik menggunakan tombol next daripada mengklik pada percakapan, 2) percakapan dibuat menarik agar siswa lebih tertarik pada media pembelajaran, 3) font huruf yang digunakan lebih diperbesar agar dapat dibaca dengan baik, 4) penulisan angka matematika harus sesuai prosedur.

Penelitian pengembangan ini telah menghasilkan suatu produk berupa media pembelajaran menggunakan adobe flash berupa alur cerita anime pokok bahasan aritmatika sosial yang dapat memberikan kemudahan bagi siswa dalam memahami konsep dan meningkatkan hasil belajar siswa. Hal ini sesuai dengan pendapat (Bayrak, C., 2008 dan Bakac, M., 2011) 
mengemukakan bahwa pengaruh pembelajaran dengan bantuan komputer terhadap hasil belajar mahasiswa. Bayrak (2008) menyatakan bahwa siswa yang belajar dengan menggunakan program pembelajaran dengan bantuan komputer lebih sukses dalam menyelesaikan pembelajaran dibandingkan dengan mahasiswa yang diajar dengan menggunakan metode kuliah konvensional pembelajaran tatap muka. Bakac (2011) juga menjelaskan terjadinya peningkatan hasil belajar pada siswa yang diajar dengan menggunakan program pembelajaran berbasis komputer, dibandingkan dengan siswa yang diajar secara konvensional. Sedangkan Salim \& Tiawa (2015) menyatakan bahwa pembelajaran dengan menggunakan teknologi dapat membantu siswa dalam memahami tentang konsep matematika, meningkatkan minat serta nalar siswa menyelesaikan masalah matematika.

Kepratisan dan keinteraktifan media pembelajaran diketahui dari hasil observasi kegiatan guru dengan rata - rata skor dari kegiatan pendahuluan, inti, dan penutup yaitu 3,17 dikategorikan baik. Selain itu hasil analisis angket siswa yang mengikuti pembelajaran menggunakan media pembelajaran dengan adobe flash berupa alur cerita anime pokok bahasan aritmatika sosial dari aspek yang dinilai menunjukan respon positif dan dapat membantu siswa dalam kegiatan pembelajaran. Berdasarkan hasil penelitian dan pembahasan, maka dapat disimpulkan sebagai berikut:

\section{KESIMPULAN DAN SARAN}

Berdasarkan hasil penelitian telah berhasil dikembangkan media pembelajaran yang valid dengan dikategorikan cukup valid dari keseluruhan aspek dari lembar validasi media pembelajaran. Dari hasil penggunaan media dalam pembelajaran menunjukan bahwa media sudah layak digunakan sebagai media pembelajaran yang diketahui dari lembar angket siswa yang memenuhi aspek aspek yang ada pada lembar angket siswa dengan dikategorikan baik.
Hasil penggunaan media dalam pembelajaran menyarankan 1) percakapan pada media pembelajaran perlu diperbaiki, 2) format tulisan dan tombol diperhatikan dan ditambahkan tombol next pada percakapan, 3) gambar anime di buat lebih menarik dan 4) perlu ditekankan pada aspke konstruktivisme siswa, 5) pembelajaran belum sampai pada penggunaan rumus mengenai laba dan rugi, dan perlu ditambahkan rumus dan penggunaan rumus rugi dan laba tersebut.

\section{DAFTAR PUSTAKA}

Arsyad, A. (2011). Media pembelajaran. Jakarta: PT. Raja.

Bakar, K., Ayub, A., \& Luan, W. T. (2010). Exploring secondary school students' motivation using technologies. Procedia Social and Behavioral Sciences 2, 4650-4654.

Bakac, M. 2011. The Effect of Computer Assisted Instruction with Simulation in Science and Physics Activities on the Success of Student: Electric Current. Eurasian J. Phys. Chem. Educ., 2(11), 34-42.

Bayrak, C. 2008. Effects of Computer Simulations Programs on University Students' Achievments in Physics. Turkish Online Journal of Distance Education-TOJDE. 9 (4) 53-62.

Branch, Robert. 2009. Instructional Design : The ADDIE Approach. Springer: USA.

Kassim, Hafizoah. (2013). The relationship between learning styles, creative thinking performance and multimedia learning materials. Procedia Social and Behavioral Sciences 97, 229-237.

Latuheru, John D. 1988. Media Pembelajaran dalam Proses Belajar-Mengajar Masa Kini. Jakarta:Depdikbud.

Rusman. 2013. Belajar dan Pembelajaran Berbasis Komputer. Alfabeta: Bandung

Salim Kalbin \& Tiawa Dayang Hjh .2015. The Student's Perceptions of Learning Mathematics using Flash Animation Secondary School in 
terakreditasi Peringkat 4 (No. SK: 36/E/KPT/2019)

Indonesia. Journal of Education Practice. 6 (34), 76-80.

Setyosari, Punaji. 2013. Metode Penilitian Pendidikan dan Pengembangan. Kencana: Jakarta.

Sujana, Nana dan Rivai, Ahmad. 2005. Media Pengajaran. Bandung: Sinar Baru Algesindo.

Yudhiantoro, Dhani. 2003. Panduan Lengkap. Kencana: Jakarta. 